\title{
OPÇÃO E EVASÃO DE UM CURSO DE GRADUAÇÃO EM ENFERMAGEM: PERCEPÇÃO DE ESTUDANTES EVADIDOS
}

Jamila Geri Tomaschewski BARLEM ${ }^{a}$, Valéria Lerch LUNARDI ${ }^{b}$, Simoní Saraiva BORDIGNON', Edison Luiz Devos BARLEM ${ }^{\mathrm{d}}$, Wilson Danilo Lunardi FILHO ${ }^{\mathrm{e}}$, Rosemary Silva da SILVEIRA ${ }^{\mathrm{f}}$, Caroline Ceolin ZACARIAS $^{\mathrm{g}}$

\section{RESUMO}

Pesquisa qualitativa, desenvolvida em Universidade Federal do Sul do Brasil, que objetivou conhecer quais foram os motivos para opção e evasão do Curso de Graduação em Enfermagem, na percepção de estudantes evadidos. A coleta de dados ocorreu mediante envio de questionário, por meio eletrônico, a dezenove estudantes evadidos. Os nove questionários devolvidos foram submetidos à Análise Textual Qualitativa, de onde emergiram duas categorias: motivos da opção pelo curso de graduação em enfermagem e motivos para evasão do curso de graduação em enfermagem. Os resultados mostraram que a opção pelo curso está associada à vocação pessoal, à percepção da enfermagem como profissão do cuidado e sua aproximação com a área da saúde. Já a evasão está relacionada à aprovação no curso de primeira opção, ao desconhecimento acerca da profissão, às dificuldades financeiras e à desvalorização profissional. Enfatiza-se a necessidade de maior disseminação do conhecimento sobre o trabalho da Enfermagem, os campos de atuação e as atribuições.

Descritores: Educação em enfermagem. Estudantes de enfermagem. Evasão escolar.

\section{RESUMEN}

Estudio cualitativo, desarrollado en una Universidad Federal del Sur de Brasil, que tuvo por objetivo conocer motivos para opción y evasión del Curso de Enfermería, en la percepción de estudiantes evadidos. Los datos fueron recolectados mediante envío de cuestionarios, por correo electrónico, a 19 estudiantes evadidos. Los 9 cuestionarios devueltos fueron sometidos al Análisis Textual Cualitativo, originando dos categorías: motivos para la opción por el curso de enfermería y motivos para la evasión del curso de enfermería. Los resultados mostraron que la opción por el curso está asociada con vocación personal, percepción de la enfermería como una profesión de cuidado y su enfoque en la salud. La evasión está relacionada a aprobación en su primera opción de curso, ignorancia sobre la profesión, dificultades financieras y devaluación profesional. Hemos demostrado la necesidad de un mayor énfasis en la difusión de conocimientos sobre el trabajo de enfermería, áreas de práctica y sus atribuciones.

Descriptores: Educación en enfermería. Estudiantes de enfermería. Abandono de los estudiantes. Título: Opción y evasión de un curso de grado en enfermería: percepción de estudiantes evadidos.

\section{ABSTRACT}

Qualitative study, developed in a Federal University in southern Brazil, aiming to know the motives for choosing and evading a Bachelor's degree programme in Nursing, in the evaded students' perception. The data were collected through a questionnaire sent by e-mail to 19 evaded students. The 9 questionnaires that returned were submitted to Qualitative Textual Analysis, and two categories emerged: motives to opt for the nursing programme and motives to evade from the nursing programme. The results showed that the option for the programme is associated to personal vocation, perception of Nursing as a profession of care, and its closeness to the health area. Evasion seems to be related to passing the first option of undergraduate programme, ignorance about the profession, financial difficulties, and professional depreciation. We demonstrated that greater emphasis should be put on promoting knowledge about the nursing work, areas of activity and attributions.

Descriptors: Education, Nursing. Nursing, Students. Student dropouts.

Title: Option and evasion of a bachelor's degree programme in nursing: evaded students' perception.

a Enfermeira, Mestranda do Programa de Pós-Graduação em Enfermagem (PPGEnf) da Universidade Federal do Rio Grande (FURG), Bolsista de Mestrado do CNPq, Membro do Núcleo de Estudos e Pesquisas em Enfermagem e Saúde (NEPES)/FURG, Rio Grande, Rio Grande do Sul, Brasil.

b Doutora em Enfermagem, Docente do PPGEnf - FURG, Bolsista de Produtividade em Pesquisa/CNPq, Líder do NEPES/FURG, Rio Grande, Rio Grande do Sul, Brasil.

c Enfermeira, Mestranda do PPGEnf da Universidade Federal de Pelotas (UFPel), Bolsista CAPES, Membro do NEPES/FURG, Pelotas, Rio Grande do Sul, Brasil.

d Mestre em Enfermagem, Doutorando do PPGEnf - FURG, Docente da Escola de Enfermagem (EEnf) - FURG, Membro do NEPES/FURG, Rio Grande, Rio Grande do Sul, Brasil.

e Doutor em Enfermagem, Docente do PPGEnf - FURG, Bolsista de Produtividade em Pesquisa/CNPq, Membro do NEPES/FURG, Rio Grande, Rio Grande do Sul, Brasil.

f Doutora em Enfermagem, Docente do PPGEnf - FURG, Líder do NEPES/FURG, Rio Grande, Rio Grande do Sul, Brasil.

g Mestre em Enfermagem, Membro do NEPES/FURG, Porto Alegre, Rio Grande do Sul, Brasil. 


\section{INTRODUÇÃO}

Optar por um curso superior é reconhecidamente uma tarefa difícil, repleta de ansiedades, dúvidas e incertezas e, também, de grandes responsabilidades, uma vez que as consequências dessa opção podem implicar insatisfação e desapontamento com o curso escolhido ${ }^{(1)}$. O simples fato de optar por um curso de graduação e, até mesmo, o ingresso na universidade não encerra tais dúvidas. Diferentemente, podem exacerbar esses sentimentos, pois as mudanças e experiências vivenciadas, durante a vida universitária, podem não atender as expectativas quanto à profissão, provocando insegurança e trazendo, muitas vezes, decepção e consequente evasão do curso $^{(2)}$.

A evasão de um curso é uma situação cada vez mais constante, sendo difícil sua compreensão e análise pela complexidade e múltiplas dimensões envolvidas em suas diferentes manifestações motivadoras em cursos superiores, sendo comum e, às vezes, pouco discutida, aparentemente, tornando-se parte de uma rotina nesses ambientes. Entendida como o processo de interrupção intencional no ciclo de estudo, a evasão pode causar prejuízos sociais, econômicos e humanos ${ }^{(2)}$.

Diversos são os motivos que podem levar o estudante a evadir-se de um curso, os quais podem estar relacionados ao próprio universo discente, tais como imaturidade, desconhecimento ou insuficiência de informações sobre o curso em que ingressou, dificuldade de adaptação ao meio acadêmico, problemas financeiros, familiares ou, ainda, insatisfação com o sistema de ensino ou, até mesmo, descontentamento com a profissão escolhida ${ }^{(3)}$.

$\mathrm{Na}$ tentativa de elucidar parte das situações que configuram essa problemática, esta pesquisa justificou-se em virtude de que a ocorrência de evasão nos cursos de graduação em enfermagem, no Brasil, é ainda um tema pouco explorado. Em decorrência disso, pouco se pode afirmar sobre suas implicações tanto para os estudantes evadidos do curso quanto para a profissão.

Partiu-se do pressuposto que um melhor conhecimento acerca dos principais motivos de evasão manifestados por estudantes evadidos do Curso de Graduação em Enfermagem poderá auxiliar na construção de estratégias para o enfrentamento dessa situação, com possíveis reflexos na qualidade do ensino. Neste contexto, a partir da constatação da ocorrência de evasões na realidade desse Curso, emergiu a seguinte questão de pesquisa: quais foram os motivos para opção e evasão do Curso de Graduação em Enfermagem, na percepção de estudantes evadidos? Assim, tivemos como objetivo conhecer quais foram os motivos para opção e evasão do Curso de Graduação em Enfermagem, na percepção de estudantes evadidos.

\section{MÉTODO}

Pesquisa qualitativa exploratório-descritiva, desenvolvida junto aos estudantes evadidos do Curso de Graduação em Enfermagem de uma Universidade Federal do Sul do Brasil. Para selecionar os sujeitos da pesquisa, foi solicitada previamente a lista dos estudantes de Enfermagem ao Sistema de Informações Acadêmicas, contendo a situação de todos os ingressantes, a partir de 2006, ano em que ocorreu a implantação do novo Projeto Pedagógico desse Curso.

De uma listagem de 280 estudantes, foram constatadas 22 evasões. Posteriormente, verificou-se junto à Secretaria da Escola de Enfermagem da respectiva Universidade, na ficha individual dos estudantes evadidos, o número de telefone e o endereço eletrônico. Após contato inicial com os sujeitos, foi possível evidenciar que dos 22 evadidos, três haviam prestado vestibular para enfermagem novamente e ingressado em outra instituição de ensino, sendo esses descartados da pesquisa.

Os demais (19) não residiam no município, encontrando-se em localidades distantes, dificultando o acesso e o contato direto para a realização da entrevista. Assim, foram enviados convites aos estudantes evadidos, via e-mail, para participarem da pesquisa, especificando suas características e objetivos.

Após o recebimento de resposta afirmativa, foram encaminhados, eletronicamente, o Termo de Consentimento Livre e Esclarecido (TCLE) e o questionário, contendo questões fechadas, para a caracterização dos sujeitos, e questões abertas, enfocando quais foram os motivos para a opção pelo curso, as vivências durante o período de permanência no curso e quais foram os motivos para a evasão, estabelecendo-se um número máximo de três envios de e-mails para obter a resposta ao instrumento. Desse modo, a coleta de dados ocorreu por meio eletrônico, nos meses de abril e maio de 2010, obtendo-se o retorno de nove questionários respondidos. 
Os dados foram analisados por meio de Análise Textual Qualitativa, a qual se desenvolveu mediante a fragmentação do material lido. Nesse processo, buscou-se integrar análise e síntese, baseadas em uma leitura exaustiva e aprofundada, descrevendo e interpretando significados e fenômenos, organizando os achados em categorias ${ }^{(4)}$.

Os preceitos éticos foram obedecidos em sua totalidade, contemplando as dimensões éticas e legais, segundo os termos da Resolução 196/96 do Conselho Nacional de Saúde ${ }^{(5)}$. O Protocolo do Projeto de Pesquisa foi aprovado, sob o $\mathrm{N}^{\circ}$ 34/2010 do Comitê de Ética em Pesquisa da Área de Saúde da Universidade Federal do Rio GrandeCEPAS/FURG.

\section{RESULTADOS}

A partir das respostas às questões fechadas, obteve-se que os nove estudantes evadidos que responderam ao questionário tinham idade entre 20 e 23 anos, sendo oito do sexo feminino e um do sexo masculino. Quatro deles haviam evadido do curso na $1^{a}$ série; três haviam evadido do curso na $2^{\text {a }}$ série, um havia evadido do curso na $3^{\text {a }}$ série, e um havia evadido do curso na $7^{\mathrm{a}}$ série. Dos nove estudantes evadidos desse Curso de Graduação em Enfermagem, seis deles ingressaram em outros cursos do ensino superior e o restante não estava exercendo nenhuma atividade acadêmica.

A partir da análise dos dados, em resposta às questões abertas, emergiram duas categorias: Motivos da opção pelo Curso de Graduação em Enfermagem e Motivos para a evasão do Curso de Graduação em Enfermagem.

\section{Motivos da opção pelo Curso de Graduação em Enfermagem}

Houve, por parte de estudantes evadidos, manifestações de que a opção pelo Curso de Graduação em Enfermagem esteve associada à vocação pessoal e à percepção da enfermagem como uma profissão do cuidado, justificando sua escolha inicial, em virtude da sua nobreza, beleza e propósitos.

Sei que todas as profissões exigem o nosso amor, a nossa dedicação de espirito, mas a enfermagem é a que mais exige, pois os melhores profissionais da enfermagem que conheço fazem de coração, fazem por amor, por paixão (E4).
Foi possível evidenciar que a aproximação dos estudantes evadidos com a profissão ocorreu a partir de vivências prévias com situações de doença familiar ou, ainda, pelo contato com pessoas próximas que atuam na enfermagem, sem a necessária e suficiente reflexão sobre a sua opção e decisão de ingresso no curso.

Hoje, eu penso que foi uma escolha imatura. Escolhi a enfermagem por ter vivenciado, meses antes da escolha, uma situação de doença familiar e, assim, tive bastante contato com hospital e profissionais da área e achei muito bonita a profissão (E2).

Pode-se perceber, também, que os entrevistados haviam optado pelo curso de enfermagem levando em consideração sua aproximação com as demais profissões da área da saúde, cujos conteúdos das disciplinas iniciais seriam comuns a outros cursos da área da saúde.

As primeiras matérias do curso são o básico de qualquer curso da área da saúde. Então, eu gostava (E5).

\section{Motivos para a evasão do Curso de Graduação em Enfermagem}

Muitos são os motivos apresentados pelos entrevistados como desencadeadores do processo de evasão do curso, uma vez que a decisão inicial da opção de cursá-lo, na maior parte das vezes, frágil e sem suficiente reflexão, pode repercutir em falsas expectativas em relação à enfermagem que, quando não atendidas, contribuem para o surgimento de sentimentos de decepção, desmotivação, perda do entusiasmo e frustração.

Na verdade, eu optei porque, além de ser um curso não tão concorrido é, consequentemente, mais acessível. $E$, por ser da área da saúde, achei que me acrescentaria alguma coisa (E7).

Assim, pode-se perceber que, no decorrer do curso, ao serem desenvolvidos conteúdos das Ciências da Enfermagem ${ }^{(6)}$ e na realização das respectivas aulas práticas, quando ocorre uma maior aproximação com o trabalho do enfermeiro, os estudantes parecem não se identificar com a profissão. Desse modo, decidem evadir-se, diante da constatação de que optaram por um curso que não corresponde aos seus interesses. 
Eu estava detestando as disciplinas práticas. Não achava a profissão de enfermagem interessante (E9).

Essa aproximação, entretanto, ocorre mais maciçamente, apenas a partir da terceira série, uma vez que, nas séries iniciais do curso, a ênfase maior é posta em conteúdos das Ciências Biológicas e da Saúde e das Ciências Humanas e Sociais, sendo as disciplinas das Ciências da Enfermagem desenvolvidas com menor carga horária, o que parece não contribuir suficientemente para o conhecimento do que seja o trabalho do enfermeiro, nas diferentes instituições de saúde.

No terceiro semestre, começamos a ver mais sobre o trabalho da enfermagem. Eu já tinha certeza que não era aquilo que eu queria, mas faltava coragem pra desistir do curso (E5).

A evasão do curso pode estar relacionada, também, a problemas financeiros, dificultando a continuidade dos estudos, repercutindo, dessa forma, em sentimentos de frustração e arrependimento. O reconhecimento da desvalorização da profissão, também, pode contribuir, no processo de decisão pela evasão, com sentimentos de inferiorização, quebra das expectativas e perda do entusiasmo em relação ao futuro profissional.

Achava desvalorizada e detestava a briga entre médicos e enfermeiros. Todo mundo me apoiou, pois sabiam que eu não gostava do curso e, também, achavam que enfermagem é uma profissão mal remunerada e que, ainda, sofre muito preconceito (E9).

A evasão também pode estar relacionada à aprovação no curso desejado em primeira opção, com sentimentos de alívio quanto à tomada de decisão de evadir-se. Diferentemente, quando o estudante decide evadir-se do curso, sem o ingresso prévio em outro, percebem-se sentimentos de medo de arrepender-se da decisão de não concluir uma graduação, de perder tempo e de não conseguir ingressar em outro curso superior, já que a permanência em uma graduação, mesmo que com insatisfação, parece garantir ao estudante o ingresso no mercado de trabalho e sua ascensão social.

Com certeza, foi o fato de estar largando uma situação segura e passar para a parte onde eu não poderia controlar os acontecimentos. E pensar que eu já tinha perdido um ano inteiro! Que faltavam só três para eu obter um diploma! (E6).

Como dificuldades no processo de evasão são apontados o medo do diálogo com os pais, a falta de coragem para evadir-se do curso e, principalmente, a perda de uma agradável adaptação ao ambiente e aos colegas. Apesar do diálogo com os pais ser mencionado como uma dificuldade, contraditoriamente, eles parecem ser fundamentais, neste processo de evasão, pois é mediante seu apoio que o estudante sente a segurança necessária para tomar a decisão percebida como a correta e mais adequada.

Eu era meio imaturo e precisei de conselhos e apoio dos meus pais, pra não cometer o erro de achar que estou errando. Pois, pela imaturidade, eu poderia ter me equivocado, na decisão de desistir (E2).

Ainda, como fator contribuinte para o processo de evasão, percebe-se a influência de colegas que, muitas vezes, também expressam suas queixas e lamentações por não estarem no curso desejado, ou seja, no curso de sua primeira opção. Exacerbam-se, assim, sentimentos de frustração e insatisfação com a situação, podendo acelerar a decisão pela evasão.

Nunca sonhei em fazer alguma coisa, só pelo fato de ser a única que eu conseguisse. Na minha turma, para não mentir dados e sendo muito otimista, no máximo, 5 colegas tinham o curso como primeira opção (E4).

\section{DISCUSSÃO}

O ingresso em determinados cursos ou áreas ultrapassa a justificativa mínima dos projetos de vida ou escolhas vocacionais, uma vez que é perceptível o ingresso de estudantes sem suficiente interesse ou conhecimento acerca de determinadas áreas escolhidas, motivados, talvez, pela maior facilidade de inserção em um determinado curso superior ou a possibilidade de sua rápida absorção no mercado de trabalho. Essas características, muito mais preocupantes que o imaginável, não ocorrem isoladamente e, por sua vez, reforçam imagens, concepções e valores que circulam socialmente, determinando a visão de determinadas profissões ${ }^{(7)}$.

Como constatado em estudo realizado com evadidos de outros cursos de graduação ${ }^{(8)}$, não parece haver uma reflexão suficiente sobre a escolha da enfermagem como opção profissional, gerando expectativas e idealizações acerca das atividades 
profissionais, que podem extrapolar o vivenciado anteriormente sobre a profissão, não alcançando correspondência com o desejado, favorecendo a emersão de sentimentos de frustração e insatisfação. Nesse sentido, já havia sido observado que a imaturidade dos jovens que ingressam na Enfermagem contribui para exacerbar as dúvidas quanto a sua opção profissional ${ }^{(9)}$.

À semelhança de nossos achados, foi identificado que, entre os motivos que direcionaram estudantes para outras áreas das ciências da saúde, estava a dificuldade ou mesmo impossibilidade em fazerem o curso de preferência, em especial medicina e odontologia ${ }^{(10)}$. A grande procura por essas carreiras conduz ao ingresso em outras profissões da saúde como segunda opção, tendo já sido constatado em outro estudo, que $70 \%$ dos estudantes ingressou na Enfermagem, por não conseguir aprovação, principalmente, na medicina ${ }^{(11)}$.

Considerando a opção profissional, cabe destacar que essa, também, pode evidenciar o processo histórico de uma profissão, seus preconceitos e suas perspectivas sociais de reconhecimento ${ }^{(12)}$. Dessa forma, a evasão parece justificar-se, em virtude do reconhecimento das poucas perspectivas profissionais, da baixa remuneração, do baixo status concedido pela profissão e da desvalorização vivenciada $^{(13-14)}$ o que contribui para o sentimento de inferiorização do estudante, ocasionando decepção com o curso em andamento e seu posterior abandono.

A visão que a sociedade manifesta acerca do profissional de enfermagem pode influenciar negativamente a identidade e auto-imagem formadas pelos estudantes de enfermagem, podendo repercutir no processo de evasão. "Tal imagem, infelizmente, é a de subalternidade e, principalmente, com referência às enfermeiras, de invisibilidade, de pouca expressividade"(15). Quando consideradas a formação e consolidação negativas dessa identidade e da auto-imagem, pode ser percebida uma formação que não parece responder às expectativas do estudante, que reconhece a desvalorização do enfermeiro, ante às dificuldades enfrentadas, já no próprio processo de formação profissional ${ }^{(16)}$.

Ainda, os estudantes, ao perceberem que a semelhança do curso de enfermagem com os demais cursos da área da saúde limita-se ao aprendizado de alguns conteúdos comuns e apenas no início da graduação, bem como aos locais de atuação e ao ser humano como seu objeto de trabalho e que a profissão tem uma forte interdependência com as demais profissões da área da saúde, o que pode levar à percepção de fragilidade para o exercício da autonomia do enfermeiro na área da saúde, reconhecem-se frustrados, com dificuldades de perceber e valorizar as possibilidades de exercício pleno da autonomia nas ações de enfermagem.

Apesar do descontentamento com o curso, no seu transcorrer, parece haver uma acomodação, em relação a essa situação, por uma insegurança em tentar a aprovação em outro processo seletivo, além de uma pressão social e familiar para a conclusão do curso superior. Portanto, torna-se difícil para muitos estudantes abandonarem o curso sem o auxílio e aprovação dos pais e da família, conforme constatado por outros estudos ${ }^{(17)}$. Evidencia-se, assim, a necessidade desse meio social e da própria instituição estarem atentos às situações vivenciadas pelos estudantes, oportunizando espaços para expressão dos seus sentimentos e expectativas em relação ao curso.

Por fim, a influência de outros colegas contribui para o processo de evasão, em virtude da visualização da sua insatisfação com o curso, uma vez que, integrar-se ao ambiente e aos colegas de curso é essencial para a consolidação da identidade profissional, considerando que, na maior parte das situações, os colegas representam fontes de apoio para o enfrentamento de dificuldades e problemas próprios da vida universitária ${ }^{(18)}$. Mesmo estudantes que tinham a enfermagem como sua primeira opção, ao verificarem que outros colegas sentem dificuldades e angústias, durante o processo de formação da identidade profissional, podem desenvolver a sensação de estarem cursando equivocadamente o curso de enfermagem, favorecendo a percepção da imaturidade da sua opção e o desejo de evadir-se.

\section{CONCLUSÕES}

O desconhecimento acerca da enfermagem, do seu trabalho e atribuições, associado à pouca reflexão do estudante no processo de opção profissional pela enfermagem, evidenciam a necessidade de uma maior ênfase na disseminação de informações acerca do trabalho do enfermeiro, dos seus diversos campos de atuação e atribuições, favorecendo a maior valorização do curso e de suas diferentes dimensões no exercício da profissão.

Considera-se que uma maior aproximação dos estudantes com a realidade profissional, mediante sua inserção mais precoce nas instituições 
de saúde, com momentos de discussão e reflexão quanto ao trabalho do enfermeiro, pode possibilitar a compreensão da enfermagem como uma ciência em construção, com ações independentes e interdependentes, favorecendo tanto a autonomia quanto a valorização profissional e pessoal.

Desse modo, mostra-se necessário não só que os estudantes do curso de enfermagem tenham contato, desde as séries iniciais, com a realidade do trabalho do enfermeiro, mas, também, que a sociedade, de uma maneira mais ampla, seja informada para bem conhecer e reconhecer as potencialidades e possibilidades da prática de enfermagem, nos seus mais diversos cenários de atuação. Portanto, urge desenvolver e utilizar estratégias de marketing na profissão.

$\mathrm{O}$ pequeno número dos participantes e a coleta de dados ter sido realizada por meio eletrônico foram algumas das limitações da pesquisa. Entretanto, em conformidade com os resultados obtidos, observou-se que se fazem necessários a continuidade e o aprofundamento do estudo sobre os motivos associados à evasão do curso de Enfermagem, podendo, dessa forma, enfrentar-se, mais objetivamente, este processo, amenizando as situações de sofrimento possivelmente envolvidas. Assim, sugere-se a realização de novos estudos que contribuam para essa perspectiva.

Ao concluir-se esta pesquisa, é preciso destacar que o conjunto das manifestações e de interpretações proposto não corresponde, necessariamente, à visão de todos os sujeitos que participaram desse estudo. Constitui-se das descrições de vivências e percepções de nove estudantes evadidos do Curso de Graduação em Enfermagem, nas quais cada um deles contribuiu com alguns dos aspectos apresentados, portanto, não significando que todas as manifestações se apliquem a todos.

\section{REFERÊNCIAS}

1 Vieira SPA. Satisfação com a escolha do curso de graduação: algumas evidências sobre os estudantes universitários da Univali/Biguaçu em segundo período [trabalho de conclusão de curso]. Biguaçu: Univali; 2008.

2 Tigrinho LMA. A evasão escolar nas instituições de ensino superior. Rev Gest Univ [Internet]. 2008 set [citado 2009 nov 15]. Disponível em: http://www.gestaouniversitaria.com.br/ edicoes/135-173/649-evasao-escolar-nas-instituicoes-de-ensino-superior.pdf
3 Ribeiro MA. O Projeto Profissional Familiar como determinante da evasão universitária - um estudo preliminar. Rev Bras Orientac Prof. 2005; $6(2): 55-70$.

4 Moraes R. Mergulhos discursivos: análise textual qualitativa entendida como processo integrado de aprender, comunicar e interferir em discursos. In: Galiazzi MC, Freitas JV, organizadores. Metodologias emergentes de pesquisa em educação ambiental. Ijuí: Ed. Unijuí; 2005.

5 Brasil. Ministério da Saúde. Conselho Nacional de Saúde. Diretrizes e normas regulamentadoras sobre pesquisa envolvendo seres humanos. Resolução 196/96 [Internet]. Brasília: CNS; 1996 [citado 2009 maio 28]. Disponível em: http://www.ufrgs. $\mathrm{br} / \mathrm{bioetica} / \mathrm{res} 19696 . \mathrm{html}$

6 Conselho Nacional de Educação, Câmara de Educação Superior. Resolução n. 3, de 07 de novembro de 2001: institui as Diretrizes Curriculares Nacionais do curso de graduação em enfermagem. Diário Oficial da República Federativa da União. Brasília (DF) 2001 nov 9; Seção 1:37.

7 Ojeda BS, Creutzberg M, Feoli AMP, Melo DS, Corbellini VL. Acadêmicos de enfermagem, nutrição e fisioterapia: a escolha profissional. Rev Latino-Am Enferm. 2009; 17(3):396-402.

8 Pereira FCB. Determinantes da evasão de alunos e os custos ocultos para as Instituições de Ensino Superior [tese]. Florianópolis: UFSC; 2003.

9 Brito AMR, Brito MJM, Silva PAB. Perfil sociodemográfico de discentes de Enfermagem de Instituições de Ensino Superior de Belo Horizonte. Esc Anna Nery. 2009; 13(2):328-33.

10 Traverso-Yepez M, Morais NA. Idéias e concepções permeando a formação profissional entre estudantes das ciências da saúde da UFRN: um olhar da psicologia social. Estud Psicol 2004; 9(2):75-86.

11 Baptista SS, Barreira IA. A Luta da enfermagem por um espaço na Universidade. Rio de Janeiro: UFRJ; 1997.

12 Kemmer LF, Silva MJP. A visibilidade do enfermeiro segundo a percepção de profissionais de comunicação. Rev Latino-Am Enferm. 2007; 15(2):191-8.

13 Oliveira RA de, Ciampone MHT. A universidade como espaço promotor de qualidade de vida: vivências e expressões dos alunos de enfermagem. Texto Contexto - Enferm. 2006; 15(2):254-61. 
14 Baggio MA, Formaggio FM. Profissional de enfermagem: compreendendo o autocuidado. Rev Gaúcha. Enferm. 2007; 28(2):233-41.

15 Waldow VR. O cuidado na saúde: as relações entre o eu, o outro e o cosmos. Petrópolis: Vozes; 2004.

16 Caccavo PV, Carvalho V. A arte da enfermagem: efêmera, graciosa e perene. Rio de Janeiro: Fábrica de livros; 2003.
17 Araújo JS, Sarriera JC. Redirecionamento da carreira profissional: uma análise compreensiva. In: Sarriera JC, Rocha KB, Pizinato A, editores. Desafios do mundo do trabalho: orientação, inserção e mudanças. Porto Alegre: Edipucrs; 2004.

18 Bardagi MP. Evasão e comportamento vocacional de universitários: estudos sobre o desenvolvimento de carreira na graduação [tese]. Porto Alegre: UFRGS; 2007.

Endereço do autor / Dirección del autor / Author's address:

Jamila Geri Tomaschewski Barlem

Rua General Bacelar, 196, ap. 109, Centro

96200-370, Rio Grande, RS

Email: jamila tomaschewski@hotmail.com 